\title{
DIFICULDADES ENFRENTADAS PELO CUIDADOR NA INCLUSÃO ESCOLAR DE CRIANÇAS COM PARALISIA CEREBRAL
}

\author{
Denize Arouca Araujo* \\ Elenice Dias Ribeiro de Paula Lima**
}

\begin{abstract}
RESUMO: A inclusão de crianças com deficiência na rede comum de ensino é um grande desafio. Associado à insegurança dos pais, muitas escolas não se sentem preparadas para receber o aluno com deficiência. De modo geral, os cuidadores, principais responsáveis por garantir o bem-estar, a assistência e a prestação de cuidados à criança, reconhecem a importância da escola em seu desenvolvimento. Porém, demonstram temores ao perceber o despreparo da instituição para receber a criança com deficiência. Sendo o cuidador um dos importantes pilares para viabilizar a inclusão escolar, este estudo teve por objetivo identificar os fatores dificultadores percebidos pelo cuidador da criança com paralisia cerebral em relação à sua entrada e permanência na escola comum. Trata-se de um estudo quantitativo, de natureza descritiva, cujos resultados revelam que a falta de formação dos professores, o despreparo físico das escolas e a falta de um estagiário são fatores percebidos pelos cuidadores como grandes dificultadores da inclusão da criança em escola comum.
\end{abstract}

Palavras-chave: Educação. Paralisia Cerebral. Cuidador.

\section{DIFFICULTIES FACED BY THE CAREGIVER, IN SCHOOL INSERTION OF CEREBRAL PALSY CHILDREN}

ABSTRACT: The insertion of disabled children in regular schools has been a challenge. The parents do not feel secure to have their children in regular schools and many schools do not feel prepared to work with the student who have special needs. Caregivers, in general, recognize the importance of school education in their child's development, but show unconfident as they become aware of the unpreparedness of the regular school to receive their child. As we consider this background and recognize the caregivers as important support for school insertion, we propose this study to investigate factors perceived by the caregivers, which hinder the inclusion of disabled children in the regular school. This is a quantitative descriptive study. Results reveal that the most difficult factors for the insertion of exceptional children in regular schools are lack of teachers' qualification, school unpreparedness and lack of a support assistant.

Keywords: Education. Cerebral Palsy. Caregivers.

\footnotetext{
* Mestre pela Escola de Enfermagem da Universidade Federal de Minas Gerais (UFMG). E-mail: dearouca@hotmail.com

** PhD, Professora Adjunto do Departamento de Enfermagem Básica da Escola de Enfermagem da Universidade Federal de Minas Gerais (UFMG). E-mail: elenice_lima@hotmail.com
} 


\section{Introdução}

A inclusão escolar de crianças com algum tipo de deficiência é fato recente na educação brasileira (GOMES; BARBOSA, 2006), resultando em desconhecimento sobre seus benefícios, tanto entre os educadores quanto entre os pais. Apesar de a ação educacional estar respaldada nas leis e apresentar grandes avanços, esse é um processo que apresenta inúmeras dificuldades, sendo um grande desafio a ser superado por todos aqueles que nele estão envolvidos (MENDES, 2006).

A possibilidade da inclusão escolar de crianças com deficiência ainda traz incertezas sobre a forma como ela acontecerá. Apesar de muitas escolas se mostrarem receptivas à chegada dessas crianças, os pais e até mesmo os educadores ainda percebem que há o despreparo ou a falta de formação para recebê-las, gerando inseguranças. Além disso, para a mãe que percebe seu filho como sendo muito indefeso e despreparado para enfrentar o mundo "lá fora", a possibilidade de se separar dele parece ser fonte de muita angústia.

Para muitos cuidadores, deixar de enxergar a criança com deficiência como totalmente dependente deles parece ser difícil. Acreditam que "sozinha" ela não será capaz de conviver, se defender, aprender, enfim, de se desenvolver (CASTRO; PICCININI, 2004). Os pais cuidadores enxergam seus filhos como extremamente privados das possibilidades que outras crianças com "desenvolvimento normal" têm, e levam certo tempo para considerar que seu filho cresceu e precisa começar a desenvolver seus próprios recursos para lidar com o mundo.

Esses cuidadores tendem a estabelecer relações de superproteção com a criança, limitando ainda mais seu desenvolvimento e reforçando a dependência emocional e a insegurança frente ao mundo. Pesquisas revelam que os pais de crianças com deficiência demonstram dificuldades em promover-lhes autonomia, prestam cuidados em demasia e ajuda excessiva nas tarefas cotidianas que a criança necessita desempenhar (SILVEIRA; NEVES, 2006).

Diante dessa realidade, a possibilidade da entrada da criança com deficiência no ambiente escolar parece ser recebida pelos pais, em um primeiro momento, com muita apreensão e medo. Esse temor é ainda reforçado pela atitude de algumas escolas comuns que se sentem despreparadas para incluir essas crianças no ambiente escolar e pouco aptas para 
enfrentar o desafio de uma educação focada no desempenho funcional, e não nas limitações iniciais ou permanentes da criança com deficiência (GOMES; BARBOSA, 2006; GOMES; REY, 2007; SILVEIRA; NEVES, 2006; SOUZA, 2005).

Em estudos realizados entre os pais de crianças com deficiência percebeu-se grande variedade de opiniões sobre qual seria o ambiente educacional mais adequado para a sua criança. Alguns pais defendem a colocação em escolas inclusivas, enquanto outros são favoráveis à escola especializada. Há, sobretudo, uma preocupação com relação ao tipo de ensino que será ministrado a esses alunos e até que ponto a escola comum está preparada para atender as necessidades educacionais da criança. Apontam, ainda, que esses pais veem os professores carentes de conhecimento sobre seu filho e com pouca disponibilidade para trocas de informação (ELKINS; VAN KRAAYENOORD; JOBLING, 2003).

Alguns pais seriam favoráveis à inclusão se houvesse recursos adicionais de apoio à inclusão. Os pais que se opunham à inclusão indicavam que a gravidade de seus filhos impedia qualquer benefício acadêmico ou social (ELKINS; VAN KRAAYENOORD; JOBLING, 2003; PALMER et al., 2001). Para muitos pais a escola comum é positiva porque proporciona interação com outros colegas (ELKINS; VAN KRAAYENOORD; JOBLING, 2003; SILVEIRA; NEVES, 2006) e possibilidade de aprendizado (COSTABILE; BRUNELLO, 2005).

Segundo o Ministério Público Federal (BRASIL, 2004), existem escolas que não acreditam nos benefícios que esses alunos poderão tirar dessa nova situação, especialmente nos casos com limitações mais graves ${ }^{1}$. Essas crianças não teriam condições de acompanhar os avanços dos demais colegas e seriam ainda mais marginalizadas e discriminadas do que nas classes e escolas especiais. Gomes e Rey (2007) colocam que esse pensamento mostra uma visão enrijecida dos espaços escolares sobre o processo de ensino e aprendizagem dessas crianças, presa a um modelo de educação formal em que o aprendizado tem de acontecer de maneira única para todos.

Segundo Enumo (2005), pesquisas mostram que os alunos com algum tipo de deficiência encontram-se incluídos apenas fisicamente no ambiente escolar. Faz-se, portanto, necessário que educadores explorem diferentes formas de ensinar, com propostas pedagógicas adequadas às necessidades de cada aluno com ou sem deficiência, possibilitando que o 
aprendizado seja possível e fazendo com que essas crianças sejam, de fato, incluídas (MITTTLER, 2003).

Estudos apontam o pouco conhecimento que a sociedade tem sobre a deficiência (GOMES; BARBOSA, 2006; MELO; MARTINS, 2007), sobretudo quando os professores precisam lidar com as crianças que apresentam alto nível de dependência. Há um descrédito no desenvolvimento e na aprendizagem dessas crianças com limitações mais graves, e a grande dependência física dificulta o trabalho do professor. Trabalhos evidenciam que, de modo geral, os professores consideram a inclusão escolar mais como uma possibilidade de socialização do que do real desenvolvimento cognitivo dessas crianças (GOMES; BARBOSA, 2006; GOMES; REY, 2007; SILVEIRA; NEVES, 2006).

Contudo, resultados de algumas pesquisas indicam aspectos positivos na inclusão. Um estudo realizado por Freitas e Castro (2004) mostrou que, apesar de os professores se considerarem despreparados para a inclusão de crianças com algum tipo de deficiência, passavam a demonstrar menor preconceito e resistência na medida em que iam convivendo com esses alunos em sala de aula. Segundo Mittler (2003), existem evidências de que as atitudes dos professores para com as crianças se tornam inclusivas a partir do momento em que passam a ter experiência direta com sua inclusão na sala de aula, buscando ampliar suas habilidades e desenvolver seu potencial.

A educação é um fator essencial na formação de qualquer cidadão, e o Ministério Público Federal (BRASIL, 2004) deixa claro o direito de acesso ao ensino básico (educação infantil, ensino fundamental e ensino médio), considerando a educação especial como um complemento que deve estar sempre presente na educação básica. O número de crianças com algum tipo de limitação matriculadas nas escolas regulares vem crescendo nos últimos anos (BRASIL, 2006a) e, além disso, o movimento de inclusão em favor de uma educação para todos entende que crianças com ou sem deficiência devem frequentar uma mesma sala de aula (BRASIL, 2007).

Uma vez evidenciado o despreparo desses educadores para lidar com essa população, fica claro que é preciso não só maior investimento dos sistemas educacionais, mas também que escola e família compartilhem cada vez mais as informações a respeito dessas crianças. Os pais, como principais cuidadores, tornam-se atores principais no processo de 
inclusão, na medida em que viabilizam ou não o acesso às informações sobre seus filhos e, principalmente, a participação destes na escola.

Diante do atual contexto da inclusão e, considerando, sobretudo, as ansiedades e preocupações manifestadas pelos cuidadores das crianças com deficiência, este estudo teve como objetivo identificar os fatores dificultadores para inclusão da criança com paralisia cerebral (PC) na escola comum, na visão dos cuidadores.

Entendemos que a inclusão de crianças com alguma deficiência requer mudanças profundas no comportamento e na atitude das famílias e de toda a sociedade e que, a partir de estudos que abordem o tema, poderemos detectar os entraves sentidos pelo cuidador e, assim, intervir de forma efetiva junto às famílias, ajudando-as no processo de inclusão escolar. Apesar de a literatura ser vasta em relação ao tema da inclusão, mostra-se restrita em abordar-lo sob o ponto de vista da família, sobretudo do cuidador. É importante identificar as dificuldades que esses cuidadores enfrentam durante a inclusão da criança em escola comum para que intervenções adequadas sejam providenciadas, a fim de ajudá-los nesse processo.

\section{Método}

\section{Tipo e Local do estudo}

Trata-se de um estudo seccional de natureza descritiva, desenvolvido na Associação Mineira de Reabilitação (AMR), entidade filantrópica sem fins lucrativos que presta atendimento clínico de assistência à saúde, sem internação. $\mathrm{Na}$ época da pesquisa, aproximadamente 420 crianças com deficiências múltiplas, principalmente com PC, na faixa etária de 0 a 12 anos, estavam sendo acompanhadas para reabilitação. A AMR presta também assistência e orientação às famílias.

\section{Amostra}

O estudo foi desenvolvido junto a 91 cuidadores de crianças com PC que estão em idade escolar, frequentando ou não a rede comum de educação infantil (até 5 anos) e ensino fundamental (a partir de 6 anos) e que são atendidas na Associação Mineira de Reabilitação (AMR). 
Para averiguar quais crianças apresentavam o diagnóstico de PC, foi feito um levantamento, através de prontuários, de todas as 420 crianças atendidas na instituição. As crianças foram selecionadas a partir do diagnóstico médico de PC e entre as que tinham entre 3 e 12 anos de idade. Além disso, foram levantadas informações sobre o grau de severidade motora e se a criança estava ou não inserida na rede escolar. A AMR contava, na época da pesquisa, com 234 crianças com diagnóstico de PC, sendo cada uma delas acompanhada por um cuidador.

A amostra foi determinada por meio de seleção aleatória dos cuidadores $(n=234)$ de acordo com critérios estatísticos, para garantir representatividade. A aleatoriedade permitiu o cálculo de estimativas dos erros envolvidos no processo de inferência. Foi utilizada uma amostragem probabilística para seleção das pessoas entrevistadas, garantindo a aleatoriedade da amostra, de forma que cada indivíduo da população tivesse a mesma chance de ser entrevistado. Para o cálculo de amostra foi considerado o nível de significância de $8,0 \%(\mathrm{p} \leq 0,08)$, que indicou a necessidade de 91 cuidadores para garantir representatividade.

A amostra foi dividida proporcionalmente conforme as seguintes situações: (1) se a criança frequenta escola comum; (2) se a criança frequenta escola especial; (3) se a criança não frequenta escola. Essa divisão garantiu a inclusão das três possibilidades no estudo. A proporção dessas três possibilidades na população e o tamanho da amostra estão apresentados na TAB. 1:

\section{TABELA 1}

DIVISÃO DA POPULAÇÃO DE CRIANÇAS COM PC ATENDIDAS NA ASSOCIAÇÃO MINEIRA DE REABILITAÇÃO, DE ACORDO COM 0 TIPO DE ESCOLA BELO HORIZONTE, MINAS GERAIS, 2009

\begin{tabular}{c|c|c|c} 
TIPO DE ESCOLA & UNIVERSO & $\%$ & AMOSTRA \\
\hline ESCOLA ESPECIAL & 27 & 11 & 11 \\
\hline ESCOLA COMUM & 139 & 52 & 54 \\
\hline SEM ESCOLA & 68 & 37 & 26 \\
\hline TOTAL & $\mathbf{2 3 4}$ & $\mathbf{1 0 0}$ & $\mathbf{9 1}$
\end{tabular}

Fonte: Dados primários levantados por meio de questionário. 


\section{Considerações éticas}

Anterior à coleta de dados, a pesquisa foi aprovada pela coordenação clínica da AMR, responsável pela equipe de reabilitação, e pelo Comitê de Ética em Pesquisa da Universidade Federal de Minas Gerais, parecer n. ETIC 598/07, de acordo com a Resolução 196/96 de 10 de outubro de 1996, do Conselho Nacional de Saúde (BRASIL, 1996b).

O convite aos cuidadores, esclarecimentos e agendamento dos horários foi feito pela própria pesquisadora, por meio contato telefônico ou pessoalmente. Durante esse primeiro contato era confirmado com o cuidador se a criança frequentava ou não a escola e qual o tipo de ensino. Em seguida, era feito um esclarecimento prévio sobre a pesquisa e verificado se o cuidador gostaria de participar. Participaram da pesquisa os cuidadores que se voluntariaram e assinaram o Termo de Consentimento Livre e Esclarecido.

\section{Critérios de inclusão e Variáveis}

Os critérios de inclusão para a entrevista foram: (1) ser a pessoa que passava a maior parte do tempo com a criança, (2) ser um dos responsáveis pelo bem-estar, pela assistência e pela prestação de cuidados à criança.

As variáveis do estudo a serem investigadas foram: (a) variáveis sociodemográficas do cuidador (sexo, idade, escolaridade, renda, ocupação, região onde mora); (b) variáveis demográficas e clínicas da criança (diagnóstico clínico, grau de severidade, tipo e frequência de tratamento); e (c) fatores percebidos pelo cuidador como dificultadores da inclusão da criança com PC em escola comum (dificuldades relacionadas ao acesso à escola, ao cuidador, ao ambiente escolar, ao despreparo da escola e à criança).

\section{Instrumento para coleta dos dados}

Para coleta de dados foi utilizado um instrumento construído pela própria pesquisadora, contendo perguntas abertas e fechadas, previa- 
mente testado por meio de teste piloto. Para verificar a validade do instrumento, foram construídas duas perguntas abertas complementares que contemplavam a essência do conteúdo total do instrumento, cujas respostas foram comparadas às perguntas do instrumento, ao final da entrevista.

\section{Coleta de dados}

A coleta de dados foi realizada na AMR, instituição campo de estudo, através de entrevistas individuais com os cuidadores após terem assinado o Termo de Consentimento Livre e Esclarecido. A maioria das entrevistas foi realizada no horário de tratamento de reabilitação da criança, não sendo necessário o deslocamento do cuidador até a instituição somente para a entrevista.

\section{Tratamento e análise dos dados}

Os dados foram inseridos no programa Statistical Program for Social Sciences (SPSS 10.1), sendo organizados, analisados e discutidos. Traçamos a seguinte trajetória nesta análise:

Caracterização da população estudada;

Identificação dos fatores dificultadores para a inclusão da criança com PC na escola comum.

\section{Resultados}

Participaram deste estudo 91 cuidadores de crianças com PC em idade escolar, correspondendo a $100 \%$ da amostra proposta. Cada cuidador era responsável por uma criança e a grande maioria $(\mathrm{n}=75 ; 82,4 \%)$ era de mães das crianças. Os outros eram avós $(\mathrm{n}=4)$, pais $(\mathrm{n}=10)$, tia $(\mathrm{n}=1)$ e irmã $(\mathrm{n}=1)$.

Pouco mais da metade das crianças do estudo (56,0\%) eram do sexo masculino. A idade média das crianças que frequentavam a escola foi de 7 anos $(n=65)$ e das crianças que não frequentavam foi de 4 anos $(n=26)$.

Das 54 crianças que se encontravam na rede comum de ensino, $59,3 \%$ frequentava o ensino fundamental e, 40,7\%, o ensino infantil. 
Entre essas, 48,1\% estavam matriculadas em escolas públicas da rede municipal, 24,1\%, na estadual, e 27,8\%, em escolas particulares, conforme demonstrado na TAB.2.

Dentro do ensino fundamental, $50 \%$ estavam em escolas municipais, 40,6\%, em estaduais, e 9\%, nas particulares. $\mathrm{Na}$ educação infantil, $54,5 \%$ frequentavam escolas particulares e $45,5 \%$ estavam nas municipais. Não houve nenhuma criança matriculada na rede estadual.

\section{TABELA 2}

DISTRIBUIÇÃO DAS CRIANC̣AS QUE FREQUENTAM ESCOLA, DE ACORDO COM 0 TIPO, REDE E NÍVEL DE ENSINO (N = 65). BELO HORIZONTE, MINAS GERAIS, 2009.

\begin{tabular}{c|ccc} 
MODALIDADE & & N & $\%$ \\
\hline TIPO DE ENSINO & Especial & 11 & 16,9 \\
& Regular & 54 & 83,1 \\
\hline REDE DE ENSINO & Municipal & 26 & 48,1 \\
(ESCOLA COMUM) & Estadual & 13 & 24,1 \\
& Particular & 15 & 27,8 \\
\hline NÍVEL DE ENSINO & Infantil & 22 & 40,7 \\
(ESCOLA COMUM) & Fundamental & 32 & 59,3 \\
& Fonte: Dados primários levantados por meio de questionário
\end{tabular}

A grande maioria das crianças $(83,1 \%)$ estava matriculada em escolas da rede comum de ensino. Esse dado é resultante, provavelmente, do atual movimento para inclusão escolar de crianças com deficiência, que prioriza a matrícula desses alunos em escolas comuns. Mudanças importantes nas políticas educacionais que regem a educação inclusiva garantem a plena permanência do aluno com deficiência em sala de aula comum, junto com seus pares de idade, e restringem os serviços especializados e as escolas especiais (BRASIL, 2008). Na perspectiva da educação inclusiva, a escola especializada deve atuar de forma articulada com o ensino comum. Esses serviços devem passar a ser complementares e/ou suplementares, oferecendo somente e principalmente o apoio necessário, através recursos pedagógicos e de acessibilidade que garantam a melhor participação da criança no ambiente escolar, não sendo substitutivas à escolarização (BRASIL, 2007).

Fortalecendo resultados de outros estudos (BRASIL, 2004; FÁVERO, 2004), a maioria dos cuidadores optou por matricular seu filho na escola somente quando o ensino passava a ser obrigatório, ou seja, para iniciar o ensino fundamental, coincidindo com a faixa etária dos 7 anos. 
A maioria dos cuidadores ( $\mathrm{n}=75 ; 82,4 \%$ ) eram as próprias mães das crianças, com idade entre 30 a 40 anos $(81,2 \%)$. Esse dado é importante ao considerarmos que, por estarem em idade laboral produtiva, esses cuidadores poderiam ter algum emprego para ajudar a renda familiar. Porém, a maioria não exercia atividade remunerada $(69,2 \%)$ por necessitar cuidar do filho dependente, tendo inclusive de levá-lo a consultas e sessões de tratamentos 2 a 5 vezes por semana (81,3\%). Dessa forma, ficavam limitados a uma renda salarial baixa, contando apenas com o "benefício" da criança (1 salário mínimo) ou com a renda do companheiro. Apesar de que, neste estudo, houve predominância da família nuclear, ou seja, mãe, pai e filhos, a sobrecarga sobre os cuidadores não parecia ser aliviada pela distribuição das tarefas relacionadas ao cuidado da criança dependente. Resultados semelhantes foram encontrados em outras pesquisas, mostrando que o cuidado fica basicamente ao encargo da mãe cuidadora, que acaba sobrecarregada com as diversas tarefas que precisa desempenhar durante o dia (FRANCISCHETTI, 2006; PETEAN; MURATA, 2000; TUNA et al., 2004). Os cuidados dispensados à criança deficiente concorriam com as tarefas de casa e a necessidade de assistência a outros filhos menores. Além disso, o companheiro geralmente tinha uma ocupação externa, limitando-se a ajudar com a renda salarial.

Reforçando resultados encontrados em outros estudos, associado à ausência de suporte da sua rede social, as mães também escolhiam se dedicar exclusivamente à criança com deficiência por não acreditarem que outras pessoas seriam capazes de cuidar tão bem de seu filho quanto elas mesmas (CASTRO; PICCININI, 2002, 2004; VIEIRA et al., 2008). As mães cuidadoras manifestaram sentimentos de insegurança em deixar seus filhos com pessoas fora do seu convívio, temendo que a criança não fosse olhada adequadamente, ou mesmo que sentisse muito a ausência da mãe que estava sempre presente. Esse comportamento não só aumentava a dependência mãe/criança como também a sobrecarga e o estresse dessa cuidadora.

No que se refere ao comprometimento motor das crianças, prevaleceu o diagnóstico clínico quadriplegia espástica de nível IV (Gross Motor Function Classification System - GMFCS - proposto por Palisano et al.,2000), indicando que a maioria das crianças era totalmente dependente. Pela sua gravidade, a maioria dessas crianças precisava ser levada para tratamentos diversos, pelo menos três vezes por semana, demandando 
total assistência e tempo do cuidador. Esses dados nos mostram a real dependência física da criança e a necessidade não somente de suporte clínico, mas de mobiliários, materiais didáticos e pedagógicos, recursos de acessibilidade (física e atitudinal) e equipamentos específicos para a efetiva participação da criança nos diversos ambientes da escola.

\section{Fatores dificultadores na inclusão da criança em escola comum}

Os fatores considerados pelos cuidadores como sendo barreiras para a inclusão da criança em escola comum foram investigados separadamente entre os que já frequentavam a escola, os que tinham suas crianças em escola especial e aqueles que optaram por manter a criança sem escola.

\section{Crianças já frequentando a escola comum}

$\mathrm{Na}$ percepção dos 56 cuidadores com crianças em escola comum, os critérios que mais contribuíram para a escolha da escola foram: a proximidade da residência com a escola $(n=28)$, a acessibilidade atitudinal dos professores, alunos e funcionários $(\mathrm{n}=16)$ e a escola ter boas referências ${ }^{2}(n=12)$ (Tabela 3). Esses dados indicam a importância de se oferecer um acesso fácil e rápido até a escola, de esta ser receptiva e não colocar barreiras para a participação da criança com necessidades especiais e também oferecer um bom método de ensino. Semelhante a outros estudos (COSTABILE; BRUNELLO, 2005), esses resultados sinalizam que os cuidadores esperam que seus filhos, apesar de apresentarem limitações, possam aprender e desenvolver todo o seu potencial, dentro de uma proposta pedagógica. 
TABELA 3

CRITÉRIOS USADOS PELOS CUIDADORES PARA ESCOLHA DA ESCOLA COMUM. BELO HORIZONTE, MINAS GERAIS, 2009.

\begin{tabular}{c|c} 
CRITÉRIO PARA ESCOLHA DA ESCOLA & FREQUÊNCIA DA CATEGORIA/RESPOSTAS \\
\hline Próximo à residência & 28 \\
\hline Acessibilidade atitudinal & 16 \\
\hline Boa referência da escola & 12 \\
\hline Encaminhamento pelo cadastro & 5 \\
\hline Estagiário de apoio & $\mathbf{5}$ \\
\hline Acessibilidade física da escola & $\mathbf{3}$ \\
\hline Segurança da escola & 3 \\
\hline Número reduzido de alunos em sala & 2
\end{tabular}

Fonte: Dados primários levantados por meio de questionário.

O acesso à escola foi mencionado como sendo uma grande dificuldade enfrentada pelos cuidadores. Muitos precisam percorrer parte a pé ou de ônibus, morando em locais de difícil acesso, com ausência de transporte adequado para a criança já com mobilidade tão limitada, impossibilitando-a ter boa frequência na escola. Muitas vezes, esse cuidador mora em região de ruas não pavimentadas, o que muito dificulta a saída de casa durante o período de chuva, ou mora em morros, verdadeiros obstáculos para o trajeto com a cadeira de rodas. Somando-se a essas dificuldades, dos $26(48,1 \%)$ que fazem uso de algum serviço de transporte, aproximadamente $58 \%$ utilizam veículos coletivos, que podem não ser adequados para pessoas com dificuldades de locomoção e em cadeiras de rodas. Há veículos adaptados, porém em quantidade insuficiente para atender a todos que demandam seus serviços, e que nem sempre garantem o trajeto entre casa e escola ou com rotas longas. Todos esses fatores tornam o percurso cansativo para a criança, além de reduzir a sua carga horária na escola pela chegada tardia e pela saída antecipada. Esses dados evidenciam a necessidade de transporte adaptado que seja compatível com as necessidades dessa população, tanto em número suficiente e horário adequado de funcionamento quanto em rotas ampliadas, diminuindo o tempo de permanência da criança no veículo e possibilitando que ela frequente o período de aula de forma efetiva.

Além dessas dificuldades, os cuidadores apontaram também a ausência ou a insuficiência dos órgãos de apoio à inclusão de crianças deficientes em escolas comuns. A grande queixa foi relativa à completa ausência desses órgaos ou, quando existentes, a morosidade com que os recursos são providenciados. 
No que diz respeito à entrada e à permanência da criança na escola comum, a maioria dos cuidadores do presente estudo $(57,4 \%)$ reagiu, inicialmente, com medo, preocupação ou insegurança ao levar a criança para a escola. Esse temor pode estar associado, muitas vezes, às conversas entre cuidadores sobre as dificuldades que enfrentam no processo de inclusão de seus filhos, e ao comportamento superprotetor, comum entre as mães cuidadoras.

Segundo Silveira e Neves (2006), o medo dos pais sobre a entrada e a permanência da criança na escola comum está relacionado ao despreparo das escolas em lidar com seu filho. Outros autores descrevem que esse medo pode estar associado também ao imaginário dos pais sobre uma situação que está por vir e que ainda não vivenciaram, sobretudo com relação à expectativa de como sua criança será tratada pela escola (BARBOSA; ROSINI; PEREIRA, 2007; COSTABILE; BRUNELLO, 2005; ELKINS; VAN KRAAYENOORD; JOBLING, 2003).

Apesar da reação negativa no início, a maioria desses cuidadores $(87,0 \%)$ achou que as escolas se mostraram receptivas e interessadas em receber suas crianças no ambiente escolar, e acreditam que a escola tem sido benéfica para a criança. Os cuidadores demonstraram dar grande valor e priorizar a escola que oferece um espaço acolhedor, cujos professores e alunos tenham atitudes positivas para com a criança com deficiência, enxergando-a com potencial para desenvolver. Na percepção de $80 \%$ dos cuidadores, as crianças tiveram adaptação rápida, e $91 \%$ disseram que elas gostam de frequentar a escola. Quase todos os cuidadores $(96,0 \%)$ afirmam não perceber nenhum tipo de discriminação no ambiente escolar para com sua criança.

Um estudo realizado por Souza (2005) mostrou que são poucos os professores que apresentam resistência em receber o aluno com deficiência. Há, no entanto, despreparo desses educadores para lidar com essas crianças e desconhecimento de suas necessidades específicas (GOMES; BARBOSA, 2006; MELO; MARTINS, 2007).

Os resultados mostraram que apenas 16 dentre os 54 cuidadores de crianças no ensino comum não indicaram preocupações referentes ao despreparo da escola. Aproximadamente metade $(n=26)$ mencionou como fator dificultador a falta de formação/instrumentalização, 25 citaram o despreparo/dificuldade para lidar com a criança, 25 mencionaram a falta de estagiário para ajudar a assistir a criança, e 20 fizeram referência à falta de equipamentos adaptados (TABELA 4). 
TABELA 4

DIFICULTADORES NA INSERC̣̃̃O DA CRIANÇA COM PC NA ESCOLA REGULAR, RELACIONADOS AO DESPREPARO DA ESCOLA (N = 54). BELO HORIZONTE, MINAS GERAIS, 2009.

\begin{tabular}{c|c} 
FATORES DIFICULTADORES & N \\
\hline Falta de formação/instrumentalização dos professores & 26 \\
\hline Despreparo/dificuldade para lidar com a criança & 25 \\
\hline Falta de estagiário de apoio & 25 \\
\hline Falta de equipamento e material adaptado & 20 \\
\hline falta de acessibilidade física & 16 \\
\hline Desinteresse do professor em ensinar & 13 \\
\hline Medo/insegurança dos professores & 10 \\
\hline Comportamento superprotetor dos professores & 07 \\
\hline Preconceito por parte dos professores & 02 \\
\hline Não há & 16
\end{tabular}

Fonte: Dados primários levantados por meio de questionário.

Os cuidadores avaliaram o despreparo dos professores para receber a criança deficiente como sendo uma das principais dificuldades da inclusão. Esse despreparo pode trazer restrições à participação das crianças com PC, afetando sua permanência na escola comum.

No presente estudo, muitos cuidadores expuseram que, vencidas as primeiras barreiras, desde a matrícula de seu filho na escola comum ao receio dos professores devido ao desconhecimento da deficiência, o próximo grande desafio é conseguir um ensino de qualidade que atenda às necessidades pedagógicas de seus filhos. Para tanto, os recursos pedagógicos são fundamentais para auxiliar os alunos com deficiência a desenvolverem suas atividades escolares, principalmente os que possuem comprometimento motor acentuado. Semelhantes resultados foram encontrados em outros estudos (COSTABILE; BRUNELLO, 2005; ELKINS; VAN KRAAYENOORD; JOBLING, 2003; SILVEIRA; NEVES, 2006).

Outro grande fator dificultador apontado pelos cuidadores foi a falta de um estagiário de apoio, visto que as crianças do presente estudo apresentavam restrições motoras importantes. Para eles, o estagiário seria a pessoa que proveria à criança o suporte necessário para acompanhar o aprendizado da turma, principalmente nos casos em que o comprometimento motor trazia maiores limitações à sua atuação em sala de aula. Verificou-se, no entanto, que os pais, muitas vezes, entendem que a presença do acompanhante deve acontecer em todos os momentos, independentemente da maior ou menor limitação da criança. No que se refere à real necessidade desse estagiário, cabe uma avaliação da escola sobre qual 
o papel desse profissional no acompanhamento dessas crianças e em quais momentos o auxílio a elas deve acontecer (BRASIL, 2007).

Em relação às dificuldades próprias da criança, os dificultadores mais detectados pelos cuidadores foram a dependência motora da criança ( $n=28)$ e sua dificuldade para o aprendizado $(n=24)$, estorvando sua participação no ambiente escolar. É interessante observar que a gravidade do quadro clínico ${ }^{3}$ não parece ser um impedidor para que os cuidadores levem seu filho para a escola. Apenas três cuidadores, cujas crianças frequentemente são internadas por problemas de saúde, mencionaram o quadro clínico como fator dificultador.

\section{TABELA 5}

DIFICULTADORES RELACIONADOS À CRIANÇA, INDICADOS PELOS CUIDADORES DE CRIANC̣AS COM PC EM ESCOLA COMUM (N = 54). BELO HORIZONTE, MINAS GERAIS, 2009.

\begin{tabular}{c|c} 
FATORES DIFICULTADORES & N \\
\hline Dificuldades pela coordenação motora & 28 \\
\hline Dificuldades no aprendizado & 24 \\
\hline Faltas frequentes & 14 \\
\hline Problemas emocionais/comportamento & 12 \\
\hline Limitação para as atividades físicas & 11 \\
\hline Falta de equipamento adaptado (cadeira) & 07 \\
\hline Dificuldade em separar da mãe & 06 \\
\hline Gravidade do quadro clínico & 03 \\
\hline Não há & 06
\end{tabular}

Fonte: Dados primários levantados por meio de questionário.

\section{Criança frequentando a escola especial}

Apenas onze crianças ainda se encontravam em escola especializada. Todos os seus cuidadores $(\mathrm{n}=11)$ disseram ter optado por esse tipo de escola por considerarem que ela está melhor preparada e adequadamente adaptada para atender as necessidades da criança com deficiência, sendo essa, portanto, a opção mais segura. Esses cuidadores não acreditam que a inclusão escolar venha a ser bem-sucedida, e manifestam resistência frente à possibilidade de seu filho vir a ser inserido no ensino regular. Quando questionados sobre quais fatores dificultam a entrada de sua criança na escola comum, suas respostas foram semelhantes às daqueles que levaram seus filhos para o ensino regular: despreparo da escola $(\mathrm{n}=$ 10), falta de estagiário $(n=9)$ e falta de equipamento/material adaptado 
$(n=9)$. No entanto, para essa população, esses fatores se mostraram com peso bastante significativo, tendo impedido a opção pela escola comum em mais de $80 \%$ dos entrevistados.

\section{TABELA 6 \\ DIFICULTADORES NA INSERÇÃO ESCOLAR, INDICADOS PELOS CUIDADORES DE CRIANÇAS COM PC QUE FREQUENTAM ESCOLA ESPECIALIZADA ( $\mathrm{N}=11)$. \\ BELO HORIZONTE, MINAS GERAIS, 2009.}

\begin{tabular}{c|c} 
FATORES DIFICULTADORES & N \\
\hline Despreparo da escola & $\mathbf{0 9}$ \\
\hline Falta do estagiário & $\mathbf{0 9}$ \\
\hline Falta de equipamento e material adaptado & $\mathbf{0 7}$ \\
\hline Preconceito & $\mathbf{0 7}$ \\
\hline Falta de acessibilidade física & $\mathbf{0 7}$ \\
\hline Dificuldade de aprendizagem & $\mathbf{0 7}$ \\
\hline Dependência motora da criança & $\mathbf{0 5}$ \\
\hline Gravidade do quadro clínico & $\mathbf{0 5}$ \\
\hline Falta de transporte & $\mathbf{0 1}$
\end{tabular}

Fonte: Dados primários levantados por meio de questionário.

\section{Criança não frequentando escola}

A amostra deste estudo incluiu 26 crianças que não estavam inseridas na rede de ensino comum ou especializada. Para os cuidadores dessas crianças, diversos foram os motivos para a não inclusão de seus filhos na escola comum. O mais prevalente foi o medo e a insegurança desses pais em colocar seu filho deficiente na escola $(n=8)$, seguido pela justificativa de não encontrar uma escola que aceitasse sua criança $(n=6)$, da pouca idade da criança $(\mathrm{n}=4)$ e da gravidade do quadro clínico $(\mathrm{n}=$ 4). Como fatores dificultadores para a inclusão escolar, esses cuidadores consideram a falta do estagiário $(n=21)$, o despreparo da escola $(n=20)$ e a falta de equipamento/material adaptado $(n=19)$.

Em estudo realizado com crianças com deficiências múltiplas (SILVEIRA; NEVES, 2006), verificou-se que os pais têm dificuldades em promover a autonomia de seus filhos, enxergando-os como eternos bebês. Os pais manifestam temor diante da possibilidade de verem seus filhos saindo de um ambiente familiar, onde estão mais protegidos, para um ambiente público, onde enfrentarão novos desafios com pessoas diferentes.

É igualmente importante destacar o medo de alguns cuidadores de seu filho ser isolado e discriminado pelos colegas e professores, seja pela limitação física seja pela gravidade motora. Em ambos os casos, a 
deficiência pode ser muito visível e é, às vezes, alvo de críticas e gozação, o que contribui para que os pais sejam acentuadamente superprotetores e as crianças tenham mais dificuldades em se separar deles.

\section{TABELA 7 \\ DIFICULTADORES NA INSERÇÃO ESCOLAR DA CRIANÇA COM PC QUE AINDA NÃO FREQUENTA ESCOLA* (N = 26). BELO HORIZONTE, MINAS GERAIS, 2009.}

\begin{tabular}{c|c} 
FATORES DIFICULTADORES & N \\
\hline Falta do estagiário & 21 \\
\hline Despreparo da escola & 20 \\
\hline Falta de equipamento e material adaptado & 19 \\
\hline Preconceito & 16 \\
\hline Dificuldade da criança em separar da mãe & 14 \\
\hline Falta de acessibilidade física & 12 \\
\hline Dependência motora da criança & 10 \\
\hline Gravidade do quadro clínico & $\mathbf{9}$ \\
\hline Dificuldade de aprendizagem & 1 \\
\hline Problema de comportamento da criança & 1 \\
\hline Não há & 1 \\
\hline Falta de transporte & 0 \\
\hline
\end{tabular}

\section{Considerações finais}

O presente estudo revelou que, apesar de serem várias as dificuldades enfrentadas pelos cuidadores de crianças com PC para que elas recebam educação escolar em rede de ensino comum, muitos as superam e não permitem que esses dificultadores impeçam a inclusão escolar de suas crianças. Muitos cuidadores indicaram serem receptivos em relação à proposta de inclusão escolar, corroborando com dados de outro estudo (BARBOSA; ROSINI; PEREIRA, 2007) que revelou atitudes positivas dos pais sobre a participação de seus filhos com PC em salas da rede comum de ensino.

Os cuidadores consideraram como fatores que mais facilitaram a inclusão da criança na escola comum a convivência com outras crianças, a possibilidade de a criança se desenvolver e aprender, e a acessibilidade atitudinal da escola. Corroborando com Bishop et al. (1999), o convívio em ambientes compartilhados estimula as relações de amizade entre crianças com e sem deficiência, favorecendo o desenvolvimento e a participação conjunta em todas as atividades escolares. 
Para as mães cuidadoras, ter seus filhos na escola pode representar também um tempo livre para si mesmas, um espaço para lazer, descanso ou trabalho remunerado. Além disso, quando essas cuidadoras veem seu filho convivendo com outras crianças e tendo as mesmas oportunidades, sentem-se mais próximas de uma rotina comum de outras mães.

Estudos recentes têm investigado as concepções dos educadores sobre o processo de inclusão de crianças com deficiência (GOMES; BARBOSA, 2006; GOMES; REY, 2007; SANT'ANA, 2005; SILVEIRA; NEVES, 2006), principalmente por se fazer necessário um levantamento das reais dificuldades apresentadas por esses profissionais, que se deparam, cada vez mais, com a chegada desses alunos em suas escolas. Sabemos que a inclusão é um processo novo e que vem gerando muitos temores sobre como lidar com esse alunado.

A inclusão não se efetiva apenas por decretos, mas por ações que possibilitem sua viabilidade. É um processo dinâmico que depende de constantes avaliações, reflexões e discussões das práticas e vivências entre todos os envolvidos para que se torne realidade. Para tal, é necessário que não só os professores sejam ouvidos, mas também os cuidadores diretamente envolvidos com a criança.

Este estudo mostrou que, na percepção dos cuidadores, os fatores que mais dificultam a inclusão da criança são: a falta de formação dos professores e de preparo das escolas para lidar com a criança deficiente, a falta de um estagiário de apoio e a falta de materiais e equipamentos adaptados. A dificuldade de acesso à escola também é um importante fator dificultador para a participação da criança no ambiente escolar, bem como a necessidade de transporte adaptado às necessidades físicas da criança. Segundo os cuidadores, não há respaldo eficaz de órgãos de apoio, a legislação facilita, mas não garante a inclusão escolar da criança com PC.

Os cuidadores de crianças frequentando escola especial apontaram o despreparo das escolas, inclusive a falta de equipamento/material adaptado, e a falta de estagiário para assistir a criança em suas necessidades, como os principais fatores dificultadores para incluírem sua criança na escola comum. Outros fatores, tais como idade, questões emocionais e comprometimento motor, também podem restringir a entrada da criança na escola.

Para os cuidadores das crianças que não estão inseridas na rede escolar, os resultados indicam que o desconhecimento das famílias sobre 
a escola comum se torna o maior impedidor para que elas frequentem esse tipo de ensino. Alegam atitudes de preconceito, porém não indicam ter vivenciado tal problema. Essa percepção nem sempre parece corresponder à realidade, visto que 81,5\% dos cuidadores de crianças que já frequentam a escola comum relataram que, apesar do despreparo geral para lidar com as crianças, as escolas são receptivas e as crianças gostam de ir à escola. A insegurança relacionada à inclusão parece estar muito mais baseada no desconhecimento desses cuidadores e na ausência da vivência.

Os resultados deixam claro que todos os cuidadores deste estudo percebem a importância de se formar profissionais de ensino que conheçam as necessidades da criança com deficiência e saibam escolher os recursos necessários para seu desenvolvimento social e cognitivo.

O estudo mostra ainda quão fundamental é que tanto cuidadores quanto educadores procurem caminhos que propiciem o melhor desenvolvimento da criança com comprometimento neuromotor, em todos os ambientes sociais, levando em consideração suas possibilidades, e não suas limitações. Todo esse movimento para que as mudanças positivas aconteçam exige paciência, confiança e um esforço contínuo de todos os envolvidos para que as dificuldades possam ser superadas.

O número de crianças com deficiência que se encontram fora do ensino comum é ainda significativo. As dificuldades e os temores apresentados pelos cuidadores de crianças fora da escola comum merecem estudos futuros, longitudinais, que permitam novas análises para que a proposta de inclusão escolar seja bem-sucedida.

Os cuidadores, de forma geral, são importantes conhecedores das necessidades de suas crianças. São eles os atores principais que viabilizam ou não o acesso às informações sobre seu filho e a participação deste na escola. Assim, é fundamental que se estabeleçam parcerias entre família e educadores para facilitar o processo de inclusão.

Por ser um processo novo e pelas dificuldades em mudar concepções, há ainda um percurso longo a ser trilhado, e a mudança de atitude dos envolvidos no processo de inclusão é primordial para seu sucesso. Os resultados desta pesquisa contribuem para uma melhor compreensão deste problema, fornecendo subsídios para a elaboração de estratégias de intervenção significativamente efetivas.

O número de crianças com deficiência que se encontram fora do ensino comum é ainda significativo e as dificuldades e os temores apre- 
sentados pelos cuidadores de crianças fora da escola comum merecem estudos futuros, longitudinais, que permitam novas análises para que a proposta de inclusão escolar possa avançar

Verificamos neste estudo a necessidade de um espaço onde as famílias possam conversar com o profissional de ensino sobre seus temores e expectativas sobre a inclusão escolar. Acreditamos que a criação de grupos de cuidadores pode ser um primeiro passo para facilitar o processo de inclusão da criança com deficiência na escola comum. 


\section{REFERÊNCIAS}

BARBOSA, A. J. G.; ROSINI, D. C.; PEREIRA, A. A. Atitudes parentais em relação à educação inclusiva. Revista Brasileira de Educação Especial, Marília, v. 13, n. 3, p. 447-458, set./dez. 2007.

BISHOP, K. D. et al. Promovendo amizades. In: STAINBACK, S.; STAINBACK, W. (Org.). Inclusão: um guia para educadores. Porto Alegre: Artmed, 1999. cap. 10, p. 184199.

BRASIL. Ministério da Saúde. Conselho Nacional de Saúde. Resolução n. 196 de 10 de outubro de 1996. Aprova as diretrizes e normas regulamentadoras de pesquisas envolvendo seres humanos. Informe epidemiológico do SUS, Brasília, ano V, n. 2, abr./jun. 1996b. Suplemento 3.

BRASIL. Ministério da Educação. Secretaria de Educação Especial. Política Nacional de Educaşão Especial na Perspectiva da Educação Inclusiva. Brasília: Ministério da Educação, 2007. Disponível em: <http://portal.mec.gov.br/seesp>. Acesso em: 08. out. 2010.

BRASIL. Ministério da Educação. Secretaria de Educação Especial. Decreto do AEE. Brasilia: Ministério da Educação, 2008. Disponível em:

$<$ http://portal.mec.gov.br/seesp>. Acesso em: 08 out. 2010.

BRASIL. Ministério Público Federal. $O$ acesso de alunos com deficiência às escolas e classes comuns da rede regular. Fundação Procurador Pedro Jorge de Melo e Silva (Org.). 2. ed. rev. e atual. Brasília: Procuradoria Federal dos Direitos do Cidadão, 2004. 59 p.

CASTRO, E. K.; PICCININI, C. A. Implicações da doença orgânica crônica na infância para as relações familiares: algumas questões teóricas. Psicologia: Reflexão e Crítica, Porto Alegre, v. 15, n. 3, p. 625-635, 2002.

CASTRO, E. K.; PICCININI, C. A experiência de maternidade de mães de crianças com e sem doença crônica no segundo ano de vida. Estudos de Psicologia (Natal), Natal, v. 9, n. 1, p. 89-99, jan./abr. 2004.

COSTABILE, C.; BRUNELLO, M. I. B. Repercussões da inclusão escolar sobre o cotidiano de crianças com deficiência: um estudo a partir do relato das famílias. Revista de Terapia Ocupacional da Universidade de São Paulo, São Paulo, v. 16, n. 3, p. 124-130, set./dez. 2005.

CRITELLI, D. M.; SPANOUDIS, S. Todos nós... Ninguém, um enfoque fenomenológico do social. São Paulo: Moraes, 1981.

ELKINS, J.; VAN KRAAYENOORD, C. E.; JOBLING, A. Parent's attitudes to inclusion of their children with special needs. Journal of Research in Special Educacional Needs, Queensland, v. 3, n. 2, p. 122-129, jul. 2003.

ENUMO, S. R. F. Avaliação assistida para crianças com necessidades educacionais especiais: um recurso auxiliar na inclusão escolar. Revista Brasileira de Educação Especial, Marília, v. 11, n. 3, p. 335-354, set./dez. 2005.

FÁVERO, E. A. G. Direitos das pessoas com deficiência: garantia de igualdade na diversidade. Rio de Janeiro: WVA, 2004. 343 p.

FRANCISCHETTI, S. S. R. A sobrecarga em cuidadores familiares de crianças portadoras de paralisia cerebral grave. 2006. 115 f. Dissertação (Mestrado em Distúrbios do Desenvolvimento) - Universidade Presbiteriana Mackenzie de São Paulo, São Paulo, 2006. 
FREITAS, S. N.; CASTRO, S. F. Representação social e educação especial: a representação dos professores de alunos com necessidades educativas especiais incluídos na classe comum do ensino regular. 2004. Disponível em: <http://www.educacaoonline.pro.br>. Acesso em: 23 jan. 2008.

GOMES, C.; BARBOSA, A. J. G. Inclusão escolar do portador de paralisia cerebral: atitudes de professores do ensino fundamental. Revista Brasileira de Educaşão Especial, Marília, v. 12, n. 1, p. 85-100, jan./abr. 2006.

GOMES, C.; REY, F. L. G. Inclusão escolar: representações compartilhadas de profissionais da educação acerca da inclusão escolar. Psicologia, Ciência e Profissão, Brasília, v. 27, n. 3, p. 406-417, set. 2007.

KAFROUNI, R.; PAN, M. A. G. S. A inclusão de alunos com necessidades educativas especiais e os impasses frente à capacitação dos profissionais da educação básica: um estudo de caso. Interação, Curitiba, v. 5, p. 31-45, jan./dez. 2001.

KRIGGER, K. W. Cerebral palsy: an overview. American Family Physician, Kansas, v. 73, n. 1, p. 91-100, jan. 2006.

MELO, F. R. L. V.; MARTINS, L. A. R. Acolhendo e atuando com alunos que apresentam paralisia cerebral na classe regular: a organização da escola. Revista Brasileira de Educação Especial, Marília, v. 13, n. 1, p. 111-130, jan./abr. 2007.

MENDES, E. G. A radicalização do debate sobre inclusão escolar no Brasil. Revista Brasileira de Educação, Rio de Janeiro, v. 11, n. 33, p. 387-559, set./dez. 2006.

MITTLER, P. Educação inclusiva: contextos sociais. Porto Alegre: Artmed, 2003.

PALISANO, R. J. et al. Validation of a model of gross motor function for children with cerebral palsy. Physical Therapy, New York, v. 80, n. 10, p. 974-985, oct. 2000.

PALMER, D. S. et al. Taking sides: parent's view on inclusion for their children with severe disabilities. Exceptional Children, Canadá, v. 67, n. 4, p. 467-484, jun. 2001.

PETEAN, E. B. L.; MURATA, M. F. Paralisia cerebral: conhecimento das mães sobre o diagnóstico e o impacto deste na dinâmica familiar. Paidéia, Ribeirão Preto, v. 10, n. 19, p. 40-46, ago./dez. 2000.

SILVEIRA, F. F.; NEVES, M. M. B. J. Inclusão escolar de crianças com deficiência múltipla: concepções de pais e professores. Psicologia: Teoria e Pesquisa, Brasília, v. 22, n. 1, p. 79-88, jan./abr. 2006.

SOUZA, C. C. Concepção do professor sobre o aluno com seqüela de paralisia cerebral e sua inclusão no ensino regular. 2005. 115 f. Dissertação (Mestrado em Educação) - Faculdade de Educação, Universidade do Estado do Rio de Janeiro, Rio de Janeiro, 2005.

TESSARO, N. S. Inclusão escolar: concepções de professores e alunos da educação regular e especial. São Paulo: Casa do Psicólogo, 2005.

TUNA, H. et al. Quality of life primary caregivers of children with cerebral palsy: a controlled study short form - 36 questionnaire. Developmental Medicine and Child Neurology, London, v. 46, n. 9, p. 647-648, sep. 2004.

VIEIRA, N. G. B. et al. O cotidiano de mães com crianças portadoras de paralisia cerebral. Revista Brasileira em Promoção da Saúde, Fortaleza, v. 21, n. 1, p. 55-60, 2008. 


\section{NOTAS}

1 O comprometimento neuromotor de uma criança com paralisia cerebral pode ser caracterizado como leve, moderado ou grave. Tal comprometimento pode resultar em limitações nas diversas atividades do cotidiano da criança, interferindo de maneira importante na sua interação com ambiente.

2 Os cuidadores relataram buscar informações sobre as escolas e dar primazia àquelas cujas referências indicavam boas condições para oferecer bom método de ensino, materialidade, espaço físico adequado e disponibilidade para receber seu filho com deficiência, ou seja, condições para que o aprendizado da criança pudesse acontecer de maneira efetiva.

3 Crianças que, além de o quadro motor ser gravemente comprometido, podem apresentar também crises convulsivas, dificuldades na alimentação, internações frequentes por problemas de saúde, entre outros comprometimentos.

Recebido: 05/03/2010

Aprovado: 04/07/2011

Contato:

Rua Timbiras, 249

Funcionarios

CEP $30140-060$

Belo Horizonte, MG

Brasil 